\title{
European Core Curriculum in Cariology for Undergraduate Dental Students
}

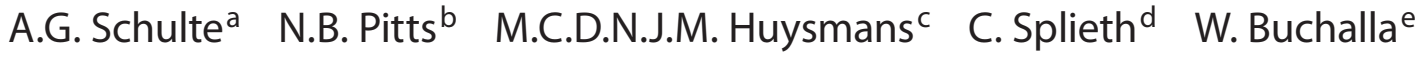

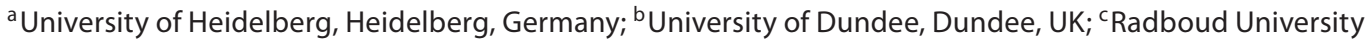 \\ Nijmegen Medical Centre, Nijmegen, The Netherlands; ${ }^{d}$ University of Greifswald, Greifswald, Germany; \\ eUniversity of Zürich, Zürich, Switzerland
}

\section{Key Words}

Dental curriculum $\cdot$ Undergraduate education · Caries ·

Caries diagnostic - Caries prevention - Caries therapy ·

Dental public health • Evidence based cariology $\cdot$ Erosion •

Non-erosive wear

\begin{abstract}
As dental caries prevalence is still high in many populations and groups of both children and adults worldwide, and as caries continues to be responsible for significant health, social and economic impacts, there is an urgent need for dental students to receive a systematic education in cariology based upon current best evidence. Although European curriculum guidelines for undergraduate students have been prepared in other dental fields over the last decade, none exist for cariology. Thus the European Organisation for Caries Research (ORCA) formed a task force to work with the Association of Dental Education in Europe (ADEE) on a European Core Curriculum in Cariology. In 2010, a workshop to develop such a curriculum was organised in Berlin, Germany, with 75 participants from 24 European and 3 North-South American countries. The Curriculum was debated by five pre-identified working groups: I The Knowledge Base; II Risk Assessment, Diagnosis and Synthesis; III Decision-making and Preventive Non-surgical Therapy; IV Decision-making
\end{abstract}

and Surgical Therapy; and V Evidence-based Cariology in Clinical and Public Health Practice and then finalised jointly by the group chairs. According to this Curriculum, on graduation, a dentist must be competent at applying knowledge and understanding of the biological, medical, basic and applied clinical sciences in order to recognise caries and make decisions about its prevention and management in individuals and populations. This document, which presents several major and numerous supporting competences, does not confine itself to dental caries alone, but refers also to dental erosion/non-erosive wear and other dental hard tissue disorders.

Copyright $\odot 2011$ S. Karger AG, Basel

\section{Introduction}

Worldwide, the prevalence of dental caries amongst adults is high as the disease affects nearly $100 \%$ of the adult population in the majority of countries [1]. Furthermore, in most countries, dental caries still affects up to

This article was first published in European Journal of Dental Education published by John Wiley \& Sons, Inc. and is published in Caries Research with permission from John Wiley \& Sons.

\section{KARGER}

Fax +41613061234 E-Mail karger@karger.ch www.karger.com (c) 2011 S. Karger AG, Basel

0008-6568/11/0454-0336\$38.00/0

Accessible online at:

www.karger.com/cre
Prof Dr Andreas Schulte

Department of Conservative Dentistry, University of Heidelberg

Im Neuenheimer Feld 400

DE-69120 Heidelberg (Germany)

Tel. +4962 2156 6024, E-Mail andreas.schulte@ med.uni-heidelberg.de 
$90 \%$ of school-aged children. Thus, it is not surprising that the World Health Organisation calls for actions for continuous improvement in oral and dental health [2]. For centuries, the main task of dentists has consisted of administering therapies for the consequences of the carious destruction of dental hard tissues. Only in the last decades has it been accepted by the dental profession that application of caries preventive measures in patients and populations also represents an important part of dental activities. All these aspects show that there is a need for dental students to receive a systematic and profound education in cariology. In Europe, the Association of Dental Education in Europe (ADEE) prepared the document 'Profiles and Competences of a European Dentist' [3] that describes primarily the general competences a dentist should have. It is the task of the various dental disciplines to formulate their own specific curriculum for the education of dental students. With regard to the education of undergraduate dental students, in various dental fields European curriculum guidelines have been prepared over the last decade but not for cariology [4-8].

Thus, in 2006, the European Organisation for Caries Research (ORCA) decided to form a task force to work on a European Core Curriculum for Cariology for undergraduate dental students. The members of this group were in alphabetical order: Ben Amaechi, Wolfgang Buchalla, Marie-Charlotte Huysmans, Nigel Pitts, Fabio Sampaio and Andreas Schulte. This group was reinforced in 2009 by the ORCA board member Christian Splieth and the ADEE representative George Vougiouklakis because ORCA and ADEE had agreed to cooperate on this project. The cariology curriculum group developed a questionnaire which was sent in 2009 to all European Dental Schools which were members of ADEE $(n=171)$. The most important finding was that $89 \%$ of the responded 123 Dental Schools supported the idea of developing a European Core Curriculum for Cariology. In 2010, a workshop on the development of a European Core Curriculum for Cariology was organised in Berlin, Germany, with 75 invited participants from 24 European countries and 3 countries from North and South America. The most important items for the European Core Curriculum for Cariology were identified and debated by five working groups. The chairs of these five working groups were authorised to use the consensus papers agreed on at the workshop and to write the Cariology Core Curriculum document that is presented here. This document was finalised by undergoing a thorough reviewing process through the co-chairs and rapporteurs of these five working groups, representing many countries across Europe.
Very soon it became clear that the term 'cariology' does not necessarily include all aspects of dental hard tissue disorders such as dental erosion and non-erosive wear. Nevertheless, this curriculum does not confine itself to the aetiology, prevention and therapy of dental caries alone, but refers also to dental erosion and non-erosive wear. In most countries, the term cariology has been used in variable ways to name departments in dental schools, lectures and courses and specific examinations. The answers on the above-mentioned questionnaires revealed that in nearly every dental school the unit(s) responsible for cariology is also in charge of the education in dental erosion and non-erosive wear. To date, no significant and short terminology to describe all aspects of dental hard tissue disorders, including caries, has been identified. Thus, throughout this document, the curriculum relates to caries, dental erosion, non-erosive wear and other dental hard tissue disorders.

The present document is structured from the general to the more specific for every section. In line with what the planning committee thought a modern dentist graduating in Europe needs to know, five domains (listed below and presented in fig. 1) have been identified representing the broad categories of cariology.

I. The knowledge base

II. Risk assessment, diagnosis and synthesis

III. Decision-making and preventive non-surgical therapy IV. Decision-making and surgical therapy

V. Evidence-based cariology in clinical and public health practice

To describe the requirements in cariology for the graduating dentist, the terms competences (table 1), knowledge and familiarity have been used by adopting the definitions that were presented in the ADEE document 'Profile and competences of a graduating European dentist - update 2009' [9]. Nevertheless, this does not necessarily mean that for each domain all the three stages of requirement were identified.

The lists of supporting competences are not intended to be prescriptive and are by no means exhaustive. The lists are included for use by educators, individual schools or countries to complete and modify to meet particular national or regional needs. In making this subdivision into major and supporting competences, ORCA and ADEE envisage that all European schools will adhere to the major competences as described in this document and acknowledge that supporting competences may vary in detail and style of implementation between schools [9]. 
Fig. 1. Inter-relationship of the five main domains representing the discipline of cariology.

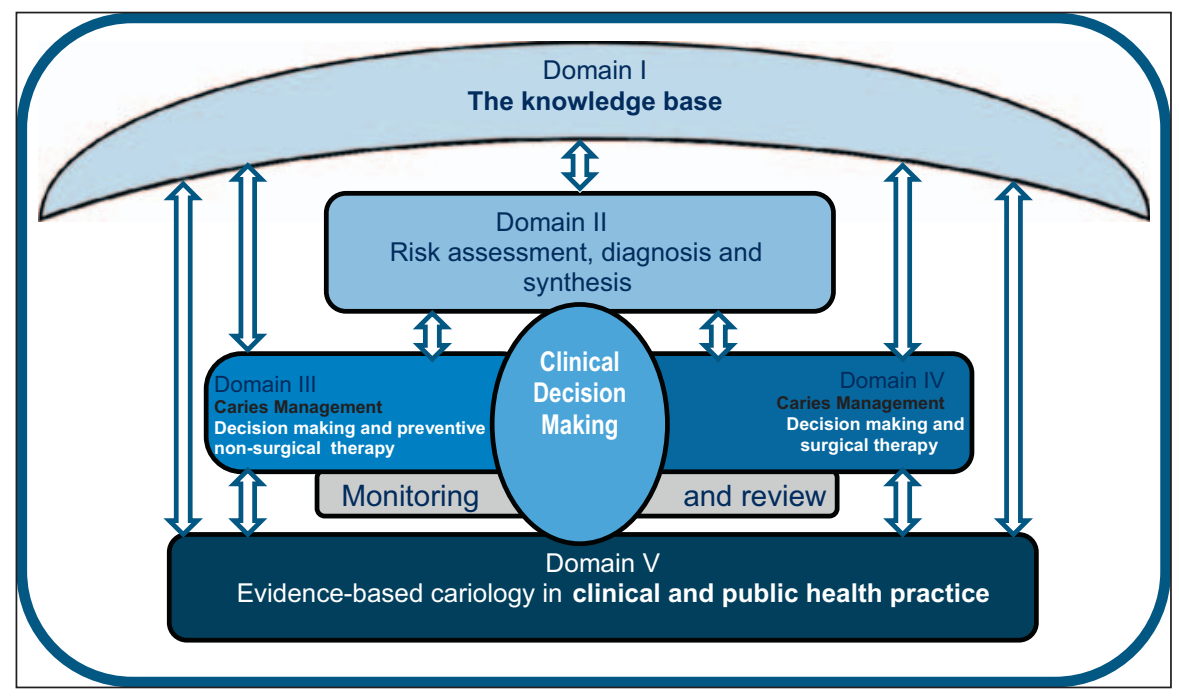

Table 1. Definitions of major and supporting competences as presented by Cowpe et al. [9]

\section{Major competences}

Within each domain, at least one 'major competence' is identified as relating to that domain's activity. A major competence is the ability of a dentist on graduation to perform or provide a particular, but complex, service or task. Its complexity suggests that multiple and more specific abilities (supporting competences) are required to support the performance of any major competence.

\section{Supporting competences}

Specific abilities could be considered as subdivisions of a major competence and are termed a supporting competence. Achievement of a major competence requires the acquisition and demonstration of all supporting competences related to that particular service or task. However, some supporting competences may also contribute to the achievement of other major competences.

Table 2. Definitions applied to the competences as presented by Cowpe et al. [9]

Be competent at: a dentist should on graduation demonstrate a sound theoretical knowledge and understanding of the subject together with an adequate clinical experience to be able to resolve clinical problems encountered independently or without assistance.

Have knowledge of: a dentist should on graduation demonstrate a sound theoretical knowledge and understanding of the subject, but may have only limited clinical/practical experience.

Be familiar with: a dentist should on graduation demonstrate a basic understanding of the subject but need not have clinical experience or be expected to carry out procedures independently.
It could be suggested that the supporting competences resemble what might be termed 'learning outcomes'. However, the information in this document describes the professional qualifications of a European Dentist, not the requirements of a course or programme of training. Having considered the definitions of competences and learning outcomes within the context of the Bologna Declaration, the term competences has been utilised. It is anticipated that the competence statements listed could support educational institutions in defining the learning outcomes, relevant to their curriculum that they would expect of a dentist on graduation. If the learning outcomes and the competency statements are in line with each other, the dentist would on graduation automatically fulfil the competency statements [9]. 'Learning outcomes support defined competences but are at a greater level of detail and form the basis of both learning and assessment. Properly constructed, competences and learning outcomes are precisely formulated to indicate what the students should know about, what the students should understand, and what the students should be able to do and how well, using language and context that indicates the level at which they will be assessed' (European Journal of Dental Education 2008).

In this ORCA/ADEE document, the definitions presented in table 2 have been applied to the competences.

The major competences described in the European Core Curriculum for Cariology mirror almost completely the seven domains described in the ADEE document 'Profile and Competences for the Graduating European Dentist' [9]. However, the domain conspicuous by its ab- 
sence is that of professionalism. The reason for this is not that it was deemed unimportant, but rather that it was deemed too important, too all encompassing to be divided into separate parts for cariology and other fields. A professional attitude and behaviour imply awareness of all skills needed for clinical dental practice and dental public health practice as well as of the dentist's responsibility to display and continuously develop those skills that include a thorough understanding, and application, of their moral, ethical and legal responsibilities. It applies equally to the field of cariology as to any other part of dentistry.

The way cariology is taught varies widely on a global scale, and even within Europe, differences in didactic and organisational approach are substantial. It is the aim of the European Core Curriculum for Cariology to provide a framework of content and goals, not to prescribe a specific way of implementation. Local differences in the organisation of higher education or oral care provision may result in specific choices, such as curricula where medical and dental students are taught together for some years, or curricula entirely based on problem-based learning. The survey amongst European dental schools showed that cariology is being taught in many different ways by many different units (A. Schulte et al., unpublished data). We hope that this new Core Curriculum for Cariology will be used, so that whatever organisational choices are made in the dental curriculum, the graduating dentist is equipped to provide appropriate care for the most widespread oral disease, caries.

\section{Domain I: The Knowledge Base}

This domain describes the foundation knowledge needed for the domains II-V. A varying depth of knowledge and understanding of each of the aspects of the knowledge base will be required in order to reach the appropriate competence levels.

\section{Major Competence}

On graduation, a dentist must be competent at applying knowledge and understanding of the biological, medical, basic and applied clinical sciences in order to recognise caries and other dental hard tissue disorders and make decisions about their prevention and management in individuals and populations.

\section{Supporting Competences}

With regard to development, growth and structure of relevant oral tissues, on graduation, a dentist must:

\section{Have knowledge of:}

1.1 Normal development, growth and structure of the dental and oral tissues (for example dental hard tissues, pulp and salivary glands) at a macroscopic, microscopic and molecular level

Be familiar with:

1.2 Developmental disorders of the dental and oral tissues at a macroscopic, microscopic and molecular level.

\section{Supporting Competences}

With regard to aetiology, pathogenesis and modifying factors of dental caries and other dental hard tissue disorders, on graduation, a dentist must:

Be competent at:

1.3 Describing and discussing the mechanisms and dynamic processes involved in maintaining a state of health, as well as the host response in caries, erosion and non-erosive wear at the macroscopic, microscopic and molecular level.

Have knowledge of:

1.4 The role of oral biofilms, diet and nutrition, saliva and other host factors, fluoride and behavioural/social factors related to caries and other dental hard tissue disorders.

1.5 Biochemical events in the biofilm, in saliva and in dental hard tissues.

1.6 Acid and base production, buffering properties and the effects of saturation in saliva and biofilm.

Be familiar with:

1.7 The role of environmental factors, drugs and systemic diseases related to caries and other dental hard tissue disorders.

\section{Supporting Competences}

With regard to detection, assessment and diagnosis, on graduation, a dentist must:

\section{Have knowledge of:}

1.8 The physical and biological basis of changes in dental hard tissues as related to detection and assessment of caries and other dental hard tissue disorders.

1.9 The physical and biological science of radiography as related to detection and assessment of caries and other dental hard tissue disorders, including safety issues.

1.10 The principles of evaluating the performance of diagnostic methods as applied to caries and other dental hard tissue disorders.

Be familiar with:

1.11 The mode of action and limitations of emerging methods for the detection, assessment and diagnosis of caries and other dental hard tissue disorders. 


\section{Supporting Competences}

With regard to behavioural sciences on graduation, a dentist must:

\section{Have knowledge of:}

1.12 The behavioural sciences including the psychological and sociological principles underlying interpersonal skills, communication and behaviour modification.

\section{Supporting Competences}

With regard to prevention and management on graduation, a dentist must:

Have knowledge of:

1.13 The mode of action, composition, properties, limitations and side effects of commonly available materials, products and techniques for the preventive non-surgical and surgical management of dental caries and other dental hard tissue disorders, at individual, group and population levels.

Be familiar with:

1.14 The theoretical basis of emerging strategies and materials for the prevention and management of dental caries and other dental hard tissue disorders.

\section{Supporting Competences}

With regard to epidemiology and research methodology on graduation, a dentist must:

Have knowledge of:

1.15 The basics of epidemiology.

1.16 The principles of risk assessment.

1.17 Research methodology and its limitations, including study design, sampling, bias and statistics.

\section{Domain II: Risk Assessment, Diagnosis and Synthesis}

This domain represents a common bridge between the knowledge base and the subsequent assessment as to the need for and choices from the increasing range of nonsurgical and surgical management options for the prevention and control of dental caries. Competences in both synthesis and clinical decision-making are needed to make evidence-informed and appropriate decisions for clinical and public health practice.

\section{Risk Assessment}

Major Competence

On graduation, the dentist must be competent at identifying and estimating the probability for a patient of developing new caries lesions or progression of existing le- sions during a specified period of time. The dentist must also be competent at applying these abilities with regard to erosion and non-erosive wear. A varying depth of knowledge and understanding is required in order to collect, record and analyse reliable, valid and clinically meaningful data, allowing the dentist to categorise patients into different risk categories for caries and, where applicable, for erosion and non-erosive wear.

\section{Supporting Competences}

On graduation, a dentist must:

Be competent at:

2.1 Obtaining data by selecting the appropriate risk factors/indicators if/when applicable from: patient's histories comprising medical, oral, dental, social and economic aspects; oral health behaviours by taking into account oral hygiene, knowledge, preferences and self-efficacy, dietary habits and intraoral biological factors; caries experience; fluoride use; and systemic health; and considering new validated risk factors, as new evidence emerges.

2.2 Communicating the results of risk assessment with patients or others and providing recommendations to enable patients to reduce the risk of developing new caries lesions and/or progression of existing lesions in the future - see domains III and IV.

Have knowledge of:

2.3 Judging emerging information on risk factors and indicators.

There is often some confusion between the term caries diagnosis, lesion detection and lesion assessment.

Caries diagnosis should imply a human professional summation of all available data. Lesion detection implies some objective method of determining whether or not a disease is present. Lesion assessment aims to characterise or monitor a lesion, once it has been detected.

\section{Diagnosis}

Major Competence

On graduation, the dentist must be competent at caries diagnosis through collecting, analysing and integrating data on signs and symptoms of dental caries and assess the activity status of a lesion on a tooth surface to arrive at an identification of past or present occurrence of the disease caries. A similar competence is required for the diagnosis of erosion and non-erosive wear. 
Supporting Competences

On graduation, a dentist must:

Be competent at:

2.4 Recognising abnormal tooth tissue and differentiating between carious and non-carious hard tissue changes or anomalies. This should encompass primary and secondary lesions in both coronal and root surfaces.

2.5 Collecting and recording data on the presence of different stages of the caries process (signs) and symptoms related to dental caries.

2.6 Assessing activity status for different stages of the caries process.

2.7 Collecting, analysing and integrating data on signs and symptoms of erosion or non-erosive wear with activity status where appropriate, in order to arrive at a diagnosis of the different types of erosion or non-erosive wear.

\section{Have knowledge of:}

2.8 Evaluating different current and emerging methods for detecting and staging the caries process and assessing the activity of carious lesions and using such information to contribute to making informed treatment decisions (see also domains III and IV).

2.9 Evaluating different current and emerging methods for detecting and staging erosion or non-erosive wear and assessing the activity of erosion or non-erosive wear and using such information to contribute to making informed treatment decisions (see also domains III and IV).

Be familiar with:

2.10 The different types of developmental anomalies and the differentiation of these conditions from caries and erosion or non-erosive wear.

Synthesis is an important step in ensuring that all the various strands of information obtained from histories, examinations and special investigations are drawn together in a systematic manner and integrated for the benefit of a specific patient at a specific time.

\section{Synthesis}

\section{Major Competence}

To ensure appropriate, continuing management of dental caries and to enable patient-centred and shared clinical decision-making, on graduation the dentist must be competent at synthesising all relevant information by combining and interpreting findings from risk assessment and diagnostic processes; patients' needs, preferences and best interests; and monitoring, review and reassessment findings, when available.

European Cariology Core Curriculum
Supporting Competences

On graduation, a dentist must:

Be competent at:

2.11 Eliciting and assessing patients' needs, preferences and best interests for the management of caries.

2.12 Making clinical decisions incorporating, when appropriate, findings from monitoring, review and reassessment of caries.

These aspects link to the clinical decision-making aspects of domains III and IV.

Have knowledge of:

2.13 Erosion and non-erosive wear, synthesising all relevant findings from histories and examinations by combining and interpreting them in order to enable patient-centred and shared clinical decision-making.

2.14 Eliciting and assessing patients' needs, preferences and best interests for the management of erosion and non-erosive wear.

2.15 Making clinical decisions incorporating, when appropriate, findings from monitoring, review and reassessment of erosion and non-erosive wear.

These aspects link to the clinical decision-making aspects of domains III and IV.

Be familiar with:

2.16 Treatment options, including when to refer to specialist medical and dental care, for other, rarer, disorders of dental hard tissues or medical illnesses causing dental hard tissue disorders.

\section{Domain III: Decision-Making and Preventive Non-Surgical Therapy}

This domain is concerned with the management of caries and other dental hard tissue disorders with an emphasis on long-term preventive care planning and maintenance. It involves applying the principles of prevention of dental hard tissue disease processes (primary prevention) and progression when it has manifested itself (secondary prevention). These competences apply in different ways to patients of all ages. Goals of prevention should be clearly defined in order for outcomes to be evaluated.

\section{Communication with Patient, Family and Community in Different Health Care Environments \\ Major Competence}

On graduation, a dentist must be competent at communicating the aspects of prevention effectively, interac- 
tively and reflectively with patients of all ages, their families and carers. The communication style has to consider the age and the social circumstances of the patient/community and the environment in which this is imparted. In the following section, the term 'patient' also refers to families and carers where appropriate.

\section{Supporting Competences}

On graduation, a dentist must:

Be competent at:

3.1 Establishing a trusting patient-dentist relationship.

3.2 Identifying patient expectations, desires, attitudes, needs and demands when considering preventive treatment planning.

3.3 Identifying the psychological, physical and social factors that might have an influence on patient compliance and thereby on the outcome of preventive measures implemented and advised.

3.4 Involving the patient to promote their understanding of the disease and enhance cooperation in professional and individual preventive measures as a contribution to their future oral health.

3.5 Obtaining informed consent for delivery of all aspects of preventive care.

3.6 Working with other members of the dental team and having a clear knowledge of their roles and responsibilities during individualised preventive care and maintenance.

3.7 Appropriately sharing information and professional knowledge with other health care professionals and knowing when to refer high caries risk patients to secondary care.

Have knowledge of:

3.8 Behavioural factors that facilitate the delivery of preventive dental care.

3.9 Patient-related factors influencing the outcome of the communication of preventive advice, for example expectations, compliance over time and manual dexterity.

3.10 Non-verbal communication skills, for example intonation, body language, sitting position and eye contact.

3.11 Behavioural interventions such as motivational interviewing.

3.12 Enabling the patient to recognise the association between oral and systemic diseases.

Be familiar with:

3.13 Culturally related differences in behaviour.

\section{Clinical Decision-Making Leading to Preventive Non-Surgical Therapy}

Major Competence

On graduation, the dentist must be competent at collecting, interpreting and synthesising all relevant information needed to formulate appropriate treatment options, which can be presented to and discussed with the patient to arrive at a shared decision for an individualised treatment plan.

This includes a preventive care strategy according to the needs, risks and compliance possibilities at the individual, family, group or community level. This non-surgical disease management should consider not only the site and tooth but also patient-related factors. This requires an awareness of the potential to change and monitor risk over time. Furthermore, the graduating dentist must be competent at systematically evaluating all preventive treatment outcomes at recall and formulating alternative treatment plans when required.

Supporting Competences

On graduation, a dentist must:

Be competent at:

3.14 Decision-making based on the synthesis as described in domain II.

3.15 Educating patients concerning the aetiology of dental hard tissue disease and encouraging them to assume responsibility for their oral health.

3.16 Educating patients concerning dietary habits relevant to oral health.

3.17 Teaching patients to perform appropriate oral hygiene measures.

3.18 Performing professional tooth cleaning.

3.19 Administering preventive agents (e.g. fluorides) appropriately.

3.20 Monitoring the effects of mechanical and chemical plaque control.

3.21 Applying sealants.

3.22 Taking into account the needs of risk groups (e.g. aged or disabled or patients with systemic or psychiatric disease).

Have knowledge of:

3.23 Mechanisms of caries prevention agents, their methods of application and administration.

3.24 Limitations and adverse effects of agents and products used in preventive care.

3.25 Destructive and protective role of diet in caries and erosion. 
Be familiar with:

3.26 The critical appraisal of new developments and how to integrate them in his/her clinical activities.

\section{Domain IV: Decision-Making and Surgical Therapy}

This domain is concerned with the management of caries and other dental hard tissue disorders with an emphasis on restorative care planning and maintenance, accompanied by continuing preventive care (see domain III). It involves applying the principles of preservation of dental hard tissues and is aligned with other aspects of restorative dentistry, endodontics and prosthodontics, as far as the execution of a restoration or a restorative treatment plan is concerned. It is recognised that the surgical intervention option is only considered when the prevention-alone options are no longer likely to succeed.

\section{Clinical Decision-Making Leading to Surgical Therapy \\ Major Competence}

On graduation, the dentist must be competent at collecting, interpreting and synthesising all relevant information needed to formulate appropriate treatment options, which can be presented to and discussed with the patient to arrive at a shared decision for an individualised treatment plan.

This requires the ability to decide when it is appropriate for surgical intervention decisions for caries and other hard tissue disorders (e.g. erosion or non-erosive wear) to be made and to understand the consequences and prognosis of such decisions.

\section{Supporting Competences}

On graduation, a dentist must:

Be competent at:

4.1 Selecting the appropriate treatment option based on a sound knowledge of the range of non-surgical and surgical treatment options available.

4.2 Recognising, understanding and managing the consequences of surgical intervention.

4.3 Continual reflection on the decision-making process and outcomes of surgical intervention.

Have knowledge of:

4.4 The reactions of the pulpo-dentinal complex to the caries process and to restorative procedures.

Be familiar with:

4.5 Success and failure rates of restorations.

\section{Surgical Therapy}

Major Competence

On graduation, a dentist must be competent at carrying out appropriate surgical treatment of caries whilst preserving tooth structure. The graduating dentist must be competent at restoring the loss of dental hard tissue in form, function and aesthetics and at the same time establishing and promoting oral health.

\section{Supporting Competences}

On graduation, a dentist must:

Be competent at:

4.6 Deciding when, how and to what extent to remove carious tissue before the placement of a restoration, considering the restorability of the tooth, preservation of tooth structure and pulp vitality.

4.7 Selecting and handling appropriate restorative materials, considering physical and chemical properties, biocompatibility and longevity.

4.8 Selecting and carrying out operative techniques appropriate for both material and case.

Have knowledge of:

4.9 The impact of restorative procedures on mucosa, periodontal tissues, occlusion and oral function.

\section{Be familiar with:}

4.10 A range of emerging methods for caries removal, comprising both identification/detection of what needs to be removed and the actual act of removal of carious tooth tissue.

4.11 A range of restorative techniques and materials.

4.12 Biomechanics of restorations.

\section{Follow-Up of Restorative Therapy}

Major Competence

On graduation, a dentist must be competent at including in the decision for appropriate recall timing for the patient the diagnosis of secondary caries and restorative failure. The graduating dentist must be competent at deciding on maintenance, repair or replacement of a restoration and at appropriate patient instruction in order to prevent the damage of the restoration.

\section{Supporting Competences}

On graduation, a dentist must:

Have knowledge of:

4.13 Assessing and monitoring treatment outcome over time.

4.14 Maintenance of restorations in order to prolong longevity. 
Be familiar with:

4.15 Health economic aspects of restorative therapy.

\section{Domain V: Evidence-Based Cariology in Clinical and Public Health Practice}

This domain deals with the core skills of evidencebased dental practice within the undergraduate curriculum, which underpins the dual facets of clinical cariology (relating particularly to individuals) and public health cariology (relating particularly to groups/societies). It should be emphasised that public health cariology requires additional competences to those listed in domains II-IV. This domain relates to caries, dental erosion, nonerosive wear and other dental hard tissue disorders.

Core competences in evidence-based dentistry, which are generic to the undergraduate curriculum as a whole and not only cariology, are integral to lifelong learning skills within dentistry. The clinical cariology competences in the assessment and management of caries for the individual patient are dealt with in domains II-IV, and for Public Health Cariology, the competences are presented within this domain in close relationship to the principles of evidence-based dentistry.

It is important that these topics are brought to life by including practical experiences within the clinical and public health environment.

\section{Dental Public Health in Relation to Cariology \\ Major Competence}

On graduation, a dentist must be competent at preventing and controlling dental caries and other dental hard tissue disorders at the group and community levels. This requires comprehensive understanding of epidemiology, health promotion and preventive strategies, their integration in oral health care systems and interaction with other oral disorders, general health, nutrition and the socio-economic context.

\section{Supporting Competences}

On graduation, a dentist must:

Be competent at:

5.1 Delivering oral disease prevention for groups.

5.2 Assessing health-related behaviours and inducing changes.

Have knowledge of:

5.3 Managing issues related to individuals' rights and interests as well as to professionals' rights, duties and interests.
5.4 Recording caries and other dental hard tissue disorders using appropriate indices at different disease levels in a public health setting.

5.5 The indices for different oral problems.

5.6 The concept of oral health-related quality of life.

5.7 The descriptive epidemiology of caries in relation to different background variables such as age, general health and socioeconomic status.

5.8 The identification of caries risk individuals and groups in populations.

5.9 The assessment of dental treatment needs from a public health perspective.

5.10 The interaction of levels of organisation for prevention (individuals, groups, population).

5.11 The interactions between caries and other oral health problems.

5.12 The organisation of dental health care and public dental health in home country.

5.13 The role of different health professionals and their interaction in public dental health.

Be familiar with:

5.14 The application of epidemiological methods in dental public health.

5.15 Trends in dental health patterns and treatment needs.

5.16 Oral health promotion and prevention for populations as part of general health promotion.

5.17 Concepts of general public health approaches in populations.

5.18 International approaches to dental health care systems.

5.19 Health economic aspects of oral health programs.

\section{Evidence-Based Cariology}

Major Competence

On graduation, a dentist must understand the benefits of practising in an evidence-based manner at both individual and public health levels and have good knowledge and skills in these areas and apply them to the fields of caries, dental erosion, nonerosive wear and other dental hard tissue disorders.

\section{Supporting Competences}

On graduation, the dentist must:

Be competent at:

5.20 Identifying uncertainty or gaps in understanding.

5.21 Formulating an answerable question and searching for evidence, using appropriate resources.

5.22 Searching for and using the most appropriate clinical guidelines. 
5.23 Critical appraisal of evidence for diagnostic methods and therapies.

5.24 Evaluating the evidence for new treatment strategies in order to decide on their implementation.

5.25 Recognising the limitations of research methodology and guidelines.

Have knowledge of:

5.26 The principles of evidence-based dentistry and the hierarchy of evidence.

5.27 The methods of communicating evidence-based dentistry to individuals, groups and populations.

5.28 The advantages and disadvantages of guidelines.

5.29 Translating research findings into clinical and public health practice.

Be familiar with:

5.30 The principles of research including study design, sampling, bias and biostatistics (related to domain I).

\section{Acknowledgements}

The authors are grateful to the co-chairs (Peter Bottenberg, Hans de Soet, Lorraine Robertson, Andreas Söhnel and Annette Wiegand) and rapporteurs (Paul Anderson, Andrew Hall, Nicola Innes, Amid Ismail and David Ricketts) of the Workshop on the Development of a European Curriculum for Cariology for their helpful comments to finalise this document. Furthermore, the contribution of Georgios Vougiouklakis who represented the Association of Dental Education in Europe (ADEE) on this workshop is acknowledged. In addition, the contribution of all workshop attendees is gratefully recognised.

\section{Conflict of Interest}

The authors confirm no conflicts of interest.

\section{References}

1 Petersen PE, Bourgeois D, Ogawa H, Estupinan-Day S, Ndiaye C: The global burden of oral diseases and risks to oral health. Bull World Health Org 2005;83:661-669.

$\checkmark 2$ Petersen PE, Estupinian-Day S, Ndiaye C: WHO's action for continuous improvement in oral health. Bull World Health Org 2005; 83:642.

3 Plasschaert AJM, Holbrook WP, Delap E, Martinez C, Walmsley AD: Profile and competences for the European dentist. Eur J Dent Educ 2005;9:98-107.
4 European Society of Endodontology: Undergraduate curriculum guidelines for endodontology. Int Endodont J 2001;34:574-580.

5 European Academy for Pediatric Dentistry: A guideline framework for undergraduate education in pediatric dentistry. Eur Arch Paediatr Dent 2009;10:114-119.

6 Hicklin SP, Albrektsson T, Hämmerle CHF: Theoretical knowledge in implant dentistry for undergraduate students. Eur J Dent Educ 2009;13(suppl 1):24-35.

7 Kossioni A, Vanobbergen J, Newton J, Müller F, Heath R: European College of Gerodontology: undergraduate curriculum guidelines in gerodontology. Gerodontology 2009;26:165-171.
8 Sanz M, Meyle J: Scope, competences, learning outcomes and methods of periodontal education within the undergraduate dental curriculum: a consensus report of the 1st European workshop on periodontal education - position paper 2 and consensus view 2 . Eur J Dent Educ 2010;14(suppl 1):25-33.

9 Cowpe J, Plasschaert A, Harzer W, VinkkaPuhakka H: Profile and competences for the graduating European dentist - update 2009. Eur J Dent Educ 2010;14:193-202. 